\title{
Resilience in the Face of the Nature's Furor: Natural Disasters and Vietnamese Households
}

\author{
TAM BANG VU \\ University of Hawaii-Hilo \\ tamv@hawaii.edu \\ ERIC IKSOON IM \\ University of Hawaii-Hilo \\ eim@hawaii.edu
}

\begin{abstract}
ARTICLE INFO
ABSTRACT

Article history:

Received:

This paper investigates the effects of natural disasters in Vietnam over the period 2002-2010. Using disaster data from the desinventa.net and

Dec. 02,2013

Received in revised form

Dec. 24, 2013

Accepted: data on other variables for 64 sub-regions from the General Statistic Office of Vietnam, we examine the impacts of natural disasters on household per capita income, residential investment, and domestic trade. The damage measures comprise the number of people killed, number of people injured, number of houses destroyed, and number of houses damaged. The results reveal that the aggregate effects of the

Keywords: natural disasters, households, per capita income, residential investment, domestic trade. disaster damages on household per capita income are insignificant and on residential investment are positive, implying the resilience of the Vietnamese people against natural disasters. We then compare and contrast the costs of disasters among different regions in Vietnam.
\end{abstract}




\section{INTRODUCTION}

The recent global warming and the consequential changes in the patterns of natural disasters have increasingly caught attention of the researchers and governments worldwide. However, researches devoting to the aftermaths of disasters, especially on a specific country, are still limited. Vietnam can make a representative case for a country with high exposure to tropical storms, long sea coast, and high rate of residential investment. Vietnamese history also shows a people with a surprising resilience in their fights against invaders and natural disasters, being very used to all adversities, "blood mixed in slime, and tears fell on rice." News media worldwide has also praised the Vietnamese for their preventive activities before each natural disaster. This fact raises the question of what is the fruition of their tireless battles against the nature's furor, while the rest of the world has shown a great deal of resilience. The paper attempts to answer this question.

Different from Noy \& Vu (2010) who estimate the macroeconomic effects of natural disasters on GDP in Vietnam using single equation estimations, this paper focuses on the microeconomic impacts of natural disasters on Vietnamese people - the household per capita income, residential investment, and domestic trade - employing simultaneous equation estimations. Using a dataset for 64 provinces and centrally-controlled municipalities (or municipality for short) in the country, we first examine the aggregate impacts of natural disasters on Vietnam as a whole. We then compare and contrast the costs of disasters among different regions in Vietnam.

Vietnam is divided into eight regions. These regions are further divided into 64 subregions of provinces and municipalities. Table 1 presents the frequency of disasters for these regions from 2002 to 2011 using data from desinventar.net web site. It shows that disasters occur more frequently in the Central Coast area but also occur throughout the country. These characteristics enable identification of impacts using 64 sub-regional panel data.

Table 1: Frequency of Disasters in Vietnam's Eight Regions for 2002-2011

\begin{tabular}{lccc}
\hline \multicolumn{1}{c}{ Region } & Number & Mean & Standard Deviation \\
\hline Red River Delta & 20 & 2.0 & 2.11 \\
Northeast & 68 & 6.8 & 7.55 \\
Northwest & 28 & 2.8 & 2.70 \\
North Central Coast & 104 & 10.4 & 7.11
\end{tabular}




\begin{tabular}{lccc} 
South Central Coast & 80 & 8 & 5.96 \\
Central Highlands & 22 & 2.2 & 1.87 \\
Southeast & 36 & 3.6 & 2.68 \\
Mekong River Delta & 56 & 5.6 & 6.59 \\
Total & $\mathbf{4 1 4}$ & $\mathbf{4 1 . 4}$ & $\mathbf{3 5 . 7 2}$ \\
\hline
\end{tabular}

Note: mean denotes the average number of disasters per year.

Source: desinventar.net

Table 2 presents types of disasters occurred in the country during 2002-2011, using data from emdat.be web site. It reveals that the coastal disasters of storms and wave surges are on average four times more than other kinds of disasters. Overall, there are 414 disaster observations in the desinventa.net dataset whereas there are only 399 disasters in the emdat.be dataset. One also observes the absence of very large events in Vietnam similar to the earthquakes in Japan or China. This characteristic makes results less susceptible to the influences of outliers.

Table 2: Types of Disasters in Vietnam's Eight Regions for 2002-2011

\begin{tabular}{lccccccc}
\hline \multicolumn{1}{c}{ Region } & Storm & Flood & Epidemic & Drought & $\begin{array}{c}\text { Land } \\
\text { Slide }\end{array}$ & Others & Total \\
\hline Red River Delta & 4 & 6 & 4 & 1 & 1 & 1 & 19 \\
Northeast & 31 & 24 & 4 & 1 & 1 & 3 & 64 \\
Northwest & 10 & 8 & 1 & 1 & 1 & 4 & 26 \\
North Central Coast & 44 & 42 & 4 & 5 & 4 & 3 & 102 \\
South Central Coast & 32 & 28 & 3 & 5 & 6 & 5 & 79 \\
Central Highlands & 7 & 8 & 2 & 1 & 2 & 1 & 21 \\
Southeast & 7 & 10 & 9 & 1 & 2 & 5 & 34 \\
Mekong River Delta & 8 & 22 & 8 & 5 & 6 & 4 & 53 \\
Total & 143 & 148 & 39 & 20 & 23 & 26 & 399 \\
\hline
\end{tabular}

Note: others consist of hailstones, extreme weathers, and miscellaneous events.

Source: emdat.be

Section two of this paper reviews the existing literature. Section three discusses the data and methodology. Section four analyzes the results, and Section five concludes by offering some policy implications based on our findings. 


\section{EXISTING RESEARCHES}

There are several research strands on disasters and income that are related to this article. The first strand is micro-development research which examines the ways in which mostly rural households prepare and deal with sudden unexpected income shocks and the households' ability to insure against them. This strand focuses on the reaction of households to changes in rainfall and draughts in the rural areas of the least developed countries and so is relevant to our microeconomic approach. Paxson (1992) uses timeseries data on regional rainfall in combination with cross-sectional data on farm household income to investigate the impact of the shocks in regional rainfall on household transitional income. The author finds that shocks to rainfall produce shocks to household income but have no direct effect on consumption. Hence, the proportion of household income that is explained by regional rainfall is only considered transitory income that has a negligible effect on household permanent income.

The second strand of research focuses on the macroeconomic impact of natural disasters. Albala-Bertrand (1993) shows evidence of either insignificant or positive impact on GDP but adverse effects on the trade and current accounts. The intuition is that the destruction reduces the stock of goods available, while it also leads to increases in the flow of spending investment for reconstruction. Skidmore \& Toya (2002) call this phenomenon the "creative destruction" evidence, which is similar to the concept introduced by Schumpeter (2008), in this case implying "investment-producing destruction". Since our paper investigates the effects of disaster damages on residential investment by Vietnamese households, these researches are relevant to our research.

In contrast to the above papers, which use simple estimation methods, we use an advanced approach of combining the fixed effect three-stage least squares estimation (FE3SLS) with the Blundell-Bond system generalized method of moments (SGMM) to control the feedback effects among several variables and the presence of lagged dependent variables. Moreover, we use microeconomic data on all households for all sectors in Vietnam instead of only farming sector as in Paxson (1992) or aggregate macroeconomic data as in Albala-Bertrand (1993).

The third strand of research investigates disaster events in a single country and so is also relevant to our work. Horwich (2000) analyzes the impacts of the Kobe earthquake of 1995 in Japan. The author provides an economic perspective of Kobe 19 months after the event and draws lessons for other countries on disaster preparedness and recovery. 
He emphasizes that human capital is the most crucial factor of production in any economy. Hence, any amount of physical capital destroyed will be recovered quickly as long as human factors are preserved.

Selcuk \& Yeldan (2001) also examine a disaster in a single country, the August 1999 earthquake in Turkey. They show that the initial impact of this earthquake on GDP may range from $-4.5 \%$ to $+0.8 \%$ of GDP, depending on specific policies carried out by the government and international donors. The authors then offer policy suggestions, of which the best is an indirect reduction in tax using government aids to individual sectors to recover their capital losses, in order to mitigate the negative effects of the earthquake.

Halliday (2006) uses a set of panel data on workers and their family migrated from El Salvador to the US to examine the impact of the 2001 earthquakes on net migration to the United States. He finds that the earthquakes reduced net migration to the United States: the average probability of northward migration falls by $37.11 \%$ for a one standard deviation rise in earthquake damage. The author concludes that the reduction in transnational migration is an ex post risk management strategy when people retain labor at home to cope with the disaster's consequences instead of the earthquake disrupting migration financing.

A common finding among all existing papers is that the effects of disaster damages are short-lived, which we utilize into our paper. However, we examine all disasters in Vietnam during 2002-2010 instead of a single event and focus on microeconomic effects on household per capita income, residential investment, and domestic trade.

\section{DATA AND METHODOLOGY}

\section{a. Data}

Since data availability is important in disaster analysis, we follow Noy \& Vu (2010) to discuss the sources of data first. Data on natural disasters and their impacts for 64 subregions in Vietnam are available from the Disaster Inventory System/Disaster Information Management System website (desinventar.net) provided by United Nations Office for Disaster Risk Reduction for the period from 1992 to 2011. Data are also available from the Emergency Events Database website (emdat.be) provided by the Center for Research Epidemiology of Disasters (CRED) for the period from 1953 to 2012. However, data from emdat.be are for each incident that might affect more than one region whereas data from desinventar.net factor out the damages for each of the 64 sub-regions, which fit microeconomic data on other variables much better than those of 
the former. Hence, we use the desinventar.net data for estimations. Since this dataset does not provide the month in which the disaster occurred, we do not weight our measures based on onset months as in Noy (2009) and Noy \& Vu (2010) for our estimations.

We use four reported measures of the magnitude of the disaster in desinventar.net to form the damage measures $(D M S)$ : (1) The number of people killed $(K I L)$; (2) the number of people injured (INJ); (3) the number of houses destroyed (HDE); and (4) the number of houses damaged $(H D A)$. The desinventa.net data for Vietnam also includes the number of people affected, but there are only a handful of data points and hence, we eliminate this variable from our estimation. Each variable is divided by its respective sub-region population to obtain per capita measure, KILP, INJP, HDEP and HDAP. Figure 1 shows the evolution of disaster damages during this time period for these four measures reported by Desinventar website.

Figure 1: The Four Aggregate Disaster Measures for 2002-2011

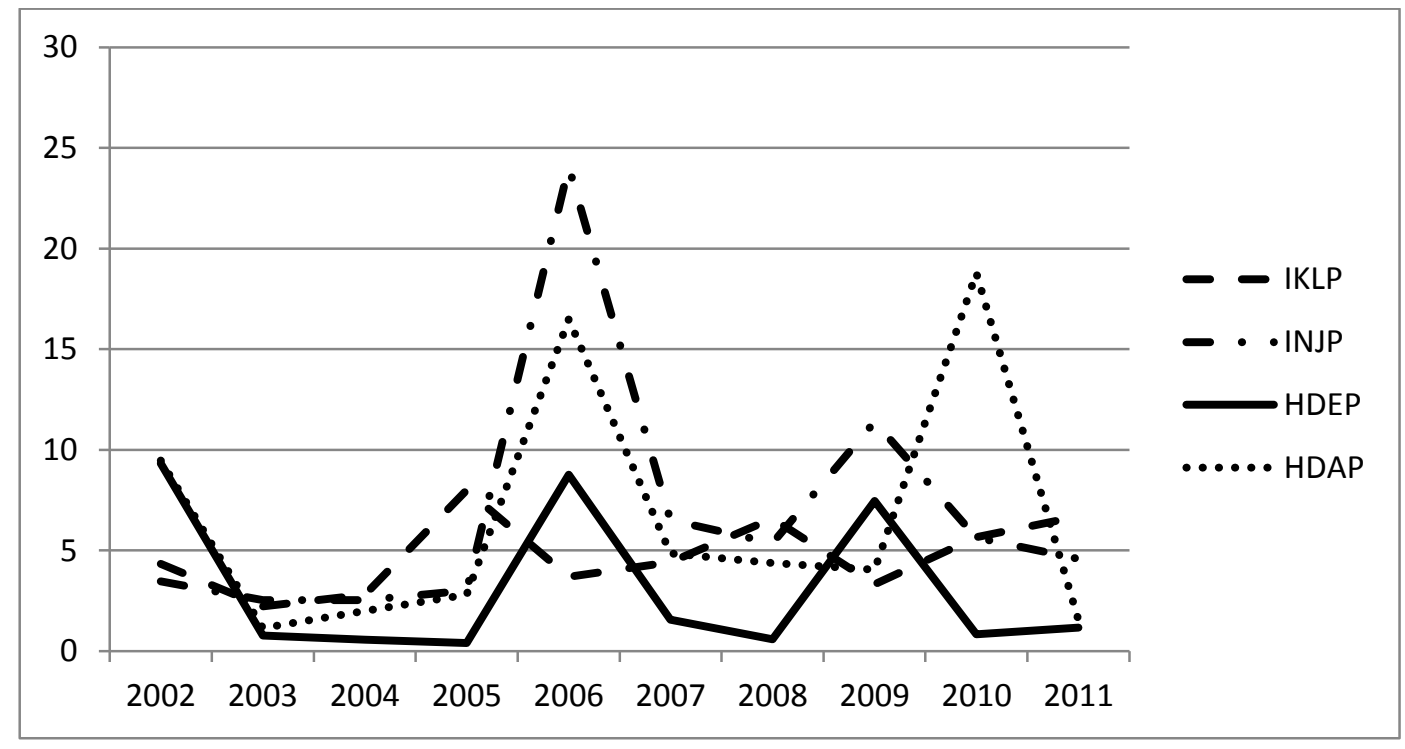

Note: $\mathrm{KILP}=$ the number of people killed per capita

INJP $=$ the number of people injured per capita

HDEP $=$ the number of house destroyed per capita

HDEP $=$ the number of house damaged per capita

Source: desinventar.net 
Table 3 reports the three largest disasters according each of the four measures for the years 2002-2011. This table once more reveals that huge events similar to the earthquakes in Japan or China do not exist in Vietnam. Hence, the use of the sub-region dataset for this research is suitable because the results will be less susceptible to the influences of outliers. Data on household per capita income and residential investment are from Vietnam Household Living Standards Survey provided by the General Statistic Office of Vietnam (GSO). They are for even years from 2002 to 2010. We project the data for odd years using a combination of weighted averaging and trending methods to obtain yearly data from 2002 to 2010 , and so this is our estimation period. This might bias the results somewhat, so we also estimate our model with the original dataset for a robustness check.

Table 3: Three Largest Natural Disasters in Each Category: 2002-2011

\begin{tabular}{lccccc}
\hline \multicolumn{1}{c}{ Sub-Region } & Year & KIL (\#) & INJ (\#) & HDES (\#) & HDAM (\#) \\
\hline By population killed & & & & & \\
Quảng Ngãi & 2008 & 325 & 301 & 24,143 & 45,248 \\
Đồng Tháp & 2006 & 150 & 316 & 21,324 & 35,454 \\
Yên Bái & 2009 & 145 & 235 & 19,243 & 51,233 \\
\hline By population injured & & & & & \\
Bà Rịa - Vũng Tàu & 2006 & 132 & 763 & 25,165 & 48,537 \\
Bến Tre & 2006 & 118 & 492 & 29,048 & 92,600 \\
Quảng Ngãi & 2009 & 127 & 348 & 23,187 & 49,275 \\
\hline By the number of houses destroyed & & & & \\
Cần Thơ & 2002 & 143 & 275 & 66,000 & 52,011 \\
Quảng Trị & 2009 & 96 & 165 & 41,800 & 42,058 \\
Bến Tre & 2006 & 118 & 492 & 29,048 & 92,600 \\
\hline By the number of houses damaged & & & & \\
Quảng Bình & 2010 & 124 & 276 & 27,956 & 162,002 \\
Bến Tre & 2006 & 118 & 492 & 29,048 & 92,600 \\
Hà Tĩnh & 2002 & 85 & 324 & 24,374 & 53,210 \\
\hline
\end{tabular}

Source: desinventar.net

Data are for monthly per capita income in current price, so we multiply the data by twelve months to obtain per capita income per year and use the consumer price index to 
convert current-price values to 1994 constant-price values. Yearly data on the stock of capital for 64 sub-regions are from the Principle Indicators of Enterprises by Regions and Provinces whereas data for other variables are from the Statistical Yearbooks; both are provided by the GSO. Table 4 presents the descriptive statistics for all variables other than the disaster damages used in this research.

Table 4: Descriptive Statistics for Other Variables

\begin{tabular}{llcc}
\hline \multicolumn{1}{c}{ Variable } & \multicolumn{1}{c}{ Unit } & Mean & $\begin{array}{c}\text { Standard } \\
\text { Deviation }\end{array}$ \\
\hline Per Capita Income & VND 1,000 & $9,510.403$ & 345 \\
Stock of Capital & VND billion & 102,867 & 1,546 \\
Freight Traffic & Ton*km & 22,057 & 804 \\
School Enrollments & 1,000 students & 125,284 & 2,523 \\
Residential Investment & Square meter per person & 15.6 & 5.27 \\
Retail Sales & VND billion & 98,272 & 8,901 \\
Medical Staffs & Persons & 3,978 & 136 \\
Population & 1,000 persons & 79,124 & 1,019 \\
Real Interest Rate & Percentage & 3.25 & 1.67 \\
\hline
\end{tabular}

Note: mean denotes the average value per year.

Yearly data on the stock of capital are for the period 2000-2008. Since capital often affects income in the long run as discussed in Barro \& Sala-i-Martin (2004), we decide to use lagged values for the variable Capital in the model. To form a proxy for human capital, we sum up primary, secondary, vocational, and technical schools and college enrollments to obtain total school enrollments. Data on the number of medical staff are used as a proxy for available health care. Data on freight traffic are used as a proxy for infrastructure. Data in current-price values are converted to constant-price values using producer price index for inputs.

The retail sale values are used as a proxy for domestic trade and also converted to the 1994 constant price using the consumer price index. All these variables are divided by population to obtain per capita measures. Data on the real interest rate (RINT) for Vietnam are from the International Monetary Fund's International Financial Statistics. We generate interacting variables by multiplying the variable RINT with the sub-regional dummy variables to account for the regional differences in financial markets, the role of 
the central government in its controlling of interest rates, and the effect of credit availability on regional trade. Data for other variables except capital are available for the whole period from 2002 to 2010 . There are missing observations, so we have an unbalanced panel, for which we use binary dummies to control for the missing observations.

\section{b. Methodology}

To reflect the possible feedback effects among the variables, we write a system of equations to be estimated simultaneously:

$$
\begin{aligned}
& Y_{i, t}=\alpha_{1} D M S_{i, t}+\alpha_{2} D M S_{i, t-1}+\beta X_{i, t}+q_{i}+s_{t}+\varepsilon_{i, t} \\
& E N D O_{i, t}=\kappa D M S_{i, t}+\kappa_{2} D M S+\phi Z_{i, t}+v_{i}+w_{t}+\omega_{i, t}
\end{aligned}
$$

Where $D M S$ are damages caused by disasters, $Y$ is per capita income, $X$ is a vector of the control variables, $E N D O$ is a vector of endogenous variables that cause feedback effects or have measurement problems, and $Z$ is a vector of variables that affect this endogenous variable. The last three terms are the regional specific disturbance, time specific disturbance, and the idiosyncratic disturbance ( $i$ and $t$ ). Note that we only enter one lagged value for $D M S$ to reflect the findings in existing literature that all damages are short-lived. We employ the Variance Inflation Factor tests (VIF), as in Kennedy (2008), to investigate the possibility of Multicollinearity. After several rounds of eliminating the highly correlated variables and performing Granger Causality tests, we have System (2), which comprises three structural equations:

$$
\begin{aligned}
& Y_{i, t}=\alpha_{1} D M S_{i, t}+\alpha_{2} D M S_{i, t-1}+\beta_{1} C A P_{i, t-2}+\beta_{2} I N I T_{i, t}+\beta_{3} I N F R_{i, t}+q_{i}+s_{t}+\varepsilon_{i, t} \\
& I N V_{i, t}=\theta_{1} D M S_{i, t}+\theta_{2} D M S_{i, t-1}+\lambda_{1} T R A D E_{i, t}+\lambda_{2} \operatorname{RINT}_{i, t}++\lambda_{3} Y_{i, t}+t_{i}+u_{t}+\varphi_{i, t} \\
& T R A D E_{i, t}=\kappa D M S_{i, t}+\kappa_{2} D M S_{i, t-1}+\mu_{1} I N V_{i, t}+\mu_{2} I N F R_{i, t} v_{i}+w_{t}+\omega_{i, t}
\end{aligned}
$$

where CAP denotes the stock of physical capital, INIT initial income level, INFRA infrastructure, $I N V$ residential investment, TRADE domestic trade, and RINT real interest rate.

From this system, one can see that per capita income does not Granger cause disaster damages $(D M S)$. However, a modified Hausman test as discussed in Kennedy (2008) reveals that each of the aforementioned $D M S$ still has an endogenous problem, probably due to measurement errors, so instrumental variables (IVs) for DMS are needed in 
addition to IVs for $Y$, INV and TRADE. Since there are feed-back effects in System (2), we estimate this system with fixed effect three stages least squares (FE3SLS) procedure. In cross sectional estimations, finding an IV is very difficult. In the panel-data estimations, lagged value of each variable can be employed as IVs. Hence, the reduced form for System (2) is written in System (3):

$$
\begin{aligned}
& D M S_{i, t}=\pi_{11} D M S_{i, t-1}+\pi_{12} C A P_{i, t i, t-2}+\pi_{13} I N F R_{i, t}+e_{i, t, 1} \\
& Y_{i, t}=\pi_{21} Y_{i, t-1}+\pi_{22} D M S_{i, t-1}+\pi_{23} I N F R_{i, t}+\pi_{24} C A P_{i, t-2}+e_{i, t, 2} \\
& I N V_{i, t}=\pi_{31} I N V_{i, t-1}+\pi_{32} D M S_{i, t-1}+\pi_{33} R I N T_{i, t}+e_{i, t, 3}(3.3) \\
& T R A D E_{i, t}=\pi_{41} T R A D E_{i, t-1}+\pi_{42} D M S_{i, t-1}+\pi_{43} I N F R_{i, t}+e_{i, t 4}
\end{aligned}
$$

To control lagged dependent variables, we estimate System (3) using the BlundellBond SGMM procedure as described in Bond (2002) and obtain the predicted values of $D M S, Y, I N V$, and TRADE to use as IVs in the FE3SLS estimations for System (2). A detailed discussion of the SGMM in Bond (2002) is available in the Appendix.

\section{RESULTS}

Table 5 shows regression results for aggregate effects of the four disaster damages in Vietnam. Since lagged values are involved, we calculate the sums of the current and lagged values and perform tests on the significance of the sums. For example, summing up current and lagged values of "Killed" in Panel (5a) gives us - 0.1091. This implies that for one percent increase in the ratio of people killed to population, there is a decrease of per capita income by VND10, 910, and the p-value of 0.476 indicates that the estimated coefficient is not significantly different from zero. The same method of calculation should be applied for the other variables. The results from Panel (5a) reveal that all four disaster damages do not affect per capita income of the households and the sum of their individual values is also insignificant.

Panel (5b) shows the effects of the four disaster damages on residential investment: they are positive and significant except for the number of people injured measure, which has negative sign and significantly so. The sum of each damage measure bears the same sign with the current effect and also statistically significant. For example, summing up current and lagged values of "Killed" in Panel (5b) gives us 2.8066. This implies that for one percent increase in the ratio of people killed to population, there is an increase of per capita investment by 2.8066 squared meters, and the p-value of 0.037 indicates 
that it is statistically significant at less than 5\% level, or exactly, at 3.7\% level. Similar interpretation is applied for the other variables.

The results also reveal that all effects are short-lived, supporting the results from existing literature. The positive effects in Panel (5b) and the insignificance in Panel (5b) imply that developing countries in general and Vietnam in particular are quite resilient. Since accumulated investment net depreciation yields stock of capital, which increases GDP, the results also imply that the increase in residential investment might indirectly help offset the negative effects of the disaster damages on per capita income. The results also appear to support the "investment-producing destruction" discussed in Skidmore \& Toya (2002).

Panel (5c) reveals that the effects of all four damages measures on domestic trade are negative and significant, confirming the results from the existing literature on the macroeconomic impact of disasters on trade in general. For example, summing up current and lagged values of "Killed" in Panel (5c) gives us -2.7593. This implies that for one percent increase in the ratio of people killed to population, there is a decrease of trade values per person by VND2.7593 million, and the p-value of 0.039 indicates that it is statistically significant at $3.9 \%$ level.

Table 5: Aggregate Effects of the Four Disaster Damages in Vietnam

Panel (5a) Dependent Variable: Per Capita Income from Households

\begin{tabular}{lcccc}
\multicolumn{1}{c}{ Variable } & Killed & Injured & $\begin{array}{c}\text { Houses } \\
\text { Destroyed }\end{array}$ & $\begin{array}{c}\text { Houses } \\
\text { Damaged }\end{array}$ \\
\hline Damage $_{\mathrm{t}}$ & .0014 & -.0002 & .0002 & .0001 \\
& $(.153)$ & $(.697)$ & $(.991)$ & $. .315)$ \\
Damage $_{\mathrm{t}-1}$ & -.1105 & .0004 & .0001 & -.0002 \\
& $(.459)$ & $(.650)$ & $(.592)$ & $(.586)$ \\
SUM of Damages & -.1091 & .0002 & .0003 & -.0001 \\
& $(.476)$ & $(.658)$ & $(.508)$ & $(.723)$ \\
CAP & $.3695 * * *$ & $.3696 * * *$ & $.3694 * * *$ & $.3697 * * *$ \\
& $(.000)$ & $(.003)$ & $(.000)$ & $(.001)$ \\
INFR & $.0006 *$ & $.0007 *$ & $.0005 *$ & $.0006^{*}$ \\
& $(.076)$ & $(.083)$ & $(.069)$ & $(.091)$ \\
INIT & $-.0003^{* *}$ & $-.0004 * *$ & $-.0004 * *$ & $-.0003 * *$
\end{tabular}




\begin{tabular}{|c|c|c|c|c|}
\hline & $(.048)$ & $(.039)$ & $(.042)$ & $(.034)$ \\
\hline \multicolumn{5}{|c|}{ Panel (5.b) Dependent Variable: Residential Investment per Person } \\
\hline \multirow[t]{2}{*}{ Damage $_{t}$} & $3.499 * * *$ & $-1.728 * * *$ & $.3943 * * *$ & $.7307 * * *$ \\
\hline & $(.000)$ & $(.009)$ & $(.003)$ & $(.000)$ \\
\hline \multirow[t]{2}{*}{ Damage $_{t-1}$} & -.6824 & -.5825 & .0336 & .0238 \\
\hline & $(.206)$ & $(.174)$ & $(.235)$ & $(.586)$ \\
\hline \multirow[t]{2}{*}{ SUM of Damages } & $2.8066^{* *}$ & $-2.3105 * *$ & $.4279 * *$ & $.7545^{* *}$ \\
\hline & $(.037)$ & $(.029)$ & $(.041)$ & $(.043)$ \\
\hline \multirow[t]{2}{*}{ TRADE } & $.9230 * * *$ & $.3245^{* *}$ & $.5178 * * *$ & $.7549 * * *$ \\
\hline & $(.006)$ & $(.019)$ & $(.009)$ & $(.000)$ \\
\hline \multirow[t]{2}{*}{ RINT } & $-.4029 * *$ & $-.4073 * * *$ & $-.4471 * *$ & $-.3950 * * *$ \\
\hline & $(.034)$ & $(.007)$ & $(.045)$ & $(.004)$ \\
\hline \multirow[t]{2}{*}{$\mathrm{Y}$} & $.0325^{* *}$ & $.0287^{*}$ & $.0412 * *$ & $.0289 *$ \\
\hline & $(.048)$ & $(.063)$ & $(.037)$ & $(.084)$ \\
\hline
\end{tabular}

\begin{tabular}{lcccc}
\hline Panel (5c) Dependent Variable: Domestic Trade Values per Person & & \\
Damage $_{\mathrm{t}}$ & $-2.969 * * *$ & $-2.083 * * *$ & $-.4124 * *$ & $-.3602 * * *$ \\
& $(.003)$ & $(.001)$ & $(.000)$ & $(.002)$ \\
Damage $_{\mathrm{t}-1}$ & .2097 & -.7478 & .2451 & -.0188 \\
& $(.651)$ & $(.315)$ & $(.412)$ & $(.561)$ \\
SUM of Damages & $-2.7593 * *$ & $-2.7308 * *$ & $-.1673 * *$ & $-.3780^{* *}$ \\
& $(.039)$ & $(.049)$ & $(.021)$ & $(.033)$ \\
INFR & $1.073^{* *}$ & $.9353 * * *$ & $.6987 * * *$ & $.7017 * * *$ \\
& $(.027)$ & $(.009)$ & $(.000)$ & $(.001)$ \\
INV & $.1457 * * *$ & $.0412 * *$ & $.1051 * *$ & $.2151 * * *$ \\
& $(.007)$ & $(.035)$ & $(.026)$ & $(.004)$ \\
\hline
\end{tabular}

Observations: 448; average RMSE for the system: 0.3254; average p-value for the model: 0.002; p-value for the White test: 0.534; p-value for the AR (1): 0.214; p-value for the AR (2): 0.857 .

Note: $* * *, * *, *$ indicate the significant level at $1 \%, 5 \%$, and $10 \%$ respectively; p-values are in parentheses.

As discussed in Greene (2003) and Wooldridge (2003), an adjusted R-squared in an IV estimation does not have a meaningful interpretation. Instead of an adjusted Rsquared, the STATA package we use provides the root mean square error (RMSE) that 
we report in each of our tables. ${ }^{1}$ A small RMSE implies a good fit of the model in addition to a p-value smaller than 0.05 .

Since the effects of damages on investment and domestic are statistically significant, we want to examine their effects on different regions in Vietnam. We use the Red River Delta region, which has the lowest frequency of disasters, as the reference group and generate seven slope dummies for the other seven regions. Table 6 and 7 report the regional effects of the four damage measures on investment and retail sales, respectively. The reference group takes on the coefficient of the damage variable in each category. Coefficients of the other groups are calculated by adding coefficient of each group to the coefficient of the reference group. Tests are performed to see if they are significantly greater, smaller than, or equal to zero and these final results are reported in the two tables.

From Table 6, one can see that most of the regions with higher frequencies of disasters do not enjoy higher investment than the base region. These results support the macroeconomic findings in Noy \& Vu (2010) concerning output and output growths in Vietnam, as accumulated investment is a crucial factor in production. For this particular period, only the Southeast, which ranks fifth in high disaster frequency and which has a higher level of development than all the other regions, has a coefficient that is significantly greater than that of the base region. This finding also supports the observation that only regions with high levels of development can enjoy capital upgrading after the occurrence of natural disasters in Cuaresma et al. (2008).

Table 6: Regional Effects of Disasters on Residential Investment in Vietnam

Dependent Variable: Residential Investment per Person

\begin{tabular}{lcccc}
\multicolumn{1}{c}{ Variable } & Killed & Injured & $\begin{array}{c}\text { Houses } \\
\text { Destroyed }\end{array}$ & $\begin{array}{c}\text { Houses } \\
\text { Damaged }\end{array}$ \\
\hline Read River Delta & $3.846^{* * *}$ & $8.791 * *$ & $.2597 * *$ & $.7876^{* * *}$ \\
& $(.003)$ & $(.026)$ & $(.032)$ & $(.000)$ \\
Northeast & $3.163^{* *}$ & $6.573 * *$ & $.3831 * * *$ & $.6729 * * *$
\end{tabular}

${ }^{1}$ Defined as $R M S E=\sqrt{\frac{1}{n} \sum_{i}\left(y_{i}-\hat{y}_{i}\right)^{2}}$. 


\begin{tabular}{|c|c|c|c|c|}
\hline & $(.035)$ & $(.018)$ & $(.002)$ & $(.002)$ \\
\hline \multirow[t]{2}{*}{ Northwest } & $2.943 * *$ & $5.326 * *$ & $.2930 * *$ & $.7231 * *$ \\
\hline & $(.047)$ & $(.048)$ & $(.043)$ & $(.023)$ \\
\hline \multirow[t]{2}{*}{ North Central Coast } & $2.525^{* *}$ & $-5.248 * *$ & $-.1901 * *$ & $-.6371 * * *$ \\
\hline & $(.027)$ & $(.025)$ & $(.028)$ & $(.009)$ \\
\hline \multirow[t]{2}{*}{ South Central Coast } & $2.717 * *$ & $-4.972 * *$ & $-.4627 * *$ & $-.7198 * *$ \\
\hline & $(.036)$ & $(.033)$ & $(.018)$ & $(.049)$ \\
\hline \multirow[t]{2}{*}{ Central Highlands } & $3.235^{* *}$ & $-3.716 * *$ & $.2867 * *$ & $.2316^{* *}$ \\
\hline & $(.042)$ & $(.028)$ & $(.035)$ & $(.039)$ \\
\hline \multirow[t]{2}{*}{ Southeast } & $6.425 * * *$ & $9.634 * * *$ & $.5934 * * *$ & $1.0862 * *$ \\
\hline & $(.005)$ & $(.004)$ & $(.000)$ & $(.044)$ \\
\hline \multirow[t]{2}{*}{ Mekong River Delta } & $3.057 * *$ & $-4.447 * *$ & .2136 & $.5743 * *$ \\
\hline & $(.026)$ & $(.027)$ & $(.048)$ & $(.036)$ \\
\hline \multirow[t]{2}{*}{ TRADE } & $.9652 * * *$ & $.6106 * * *$ & $.5256 * * *$ & $.7482 * * *$ \\
\hline & $(.009)$ & $(.005)$ & $(.000)$ & $(.000)$ \\
\hline \multirow[t]{2}{*}{ RINT } & $-.3293 * *$ & $-.3196 *$ & $-.2497 *$ & $-.2993 * * *$ \\
\hline & $(.049)$ & $(.059)$ & $(.093)$ & $(.004)$ \\
\hline \multirow[t]{2}{*}{$\mathrm{Y}$} & $.0412 *$ & $.0326 * *$ & $.0398 *$ & $.0289 *$ \\
\hline & $(.071)$ & $(.024)$ & $(.085)$ & $(.094)$ \\
\hline
\end{tabular}

Observations: 448; average RMSE for the system: 0.4648; average p-value for the model: 0.000; p-values for White test: 0.734; p-value for the AR (1): 0.198; p-value for the AR (2): 0.649.

Notes: $* * *, * *, *$ indicate the significant level at $1 \%, 5 \%$, and $10 \%$ respectively; p-values are in parentheses.

Table 7 reveals huge disparity in the effects of disasters on domestic trade among the sub-regions. There is also a noteworthy result: South Vietnam suffers much less severe effects than North Vietnam. This seems to confirm the observation that the market economy in South Vietnam from 1955 to 1975 provided the South with much needed commercial and management skills for the later period to recover quickly from any damages on its regional trade. Even the least developed regions in the South such as Central Highlands and Mekong River Delta are still suffering less severe consequences to their trade than the Northern regions. 
Table 7: Regional Effects of Disasters on Domestic Trade in Vietnam

\begin{tabular}{|c|c|c|c|c|c|}
\hline \multicolumn{6}{|c|}{ Dependent Variable: Domestic Trade Values per Person } \\
\hline \multicolumn{2}{|c|}{ Variable } & Killed & Injured & $\begin{array}{c}\text { Houses } \\
\text { Destroyed }\end{array}$ & $\begin{array}{c}\text { Houses } \\
\text { Damaged }\end{array}$ \\
\hline \multirow{2}{*}{\multicolumn{2}{|c|}{ Read River Delta }} & $-4.901 * * *$ & $-4.185 * * *$ & $-.9452 * * *$ & $-.4284 * * *$ \\
\hline & & $(.000)$ & $(.000)$ & $(.006)$ & $(.000)$ \\
\hline \multirow{2}{*}{\multicolumn{2}{|c|}{ Northeast }} & $-4.823 * *$ & $-2.475 * * *$ & $-.9159 * *$ & $-.4329 * * *$ \\
\hline & & $(.038)$ & $(.000)$ & $(.032)$ & $(.001)$ \\
\hline \multirow{2}{*}{\multicolumn{2}{|c|}{ Northwest }} & $-4.282 * * *$ & $-2.933 * *$ & $-.9832 * *$ & $-.4825 * *$ \\
\hline & & $(.003)$ & $(.015)$ & $(.031)$ & $(.046)$ \\
\hline \multirow[t]{2}{*}{ North } & Central & $-5.287 * *$ & $-4.632 * * *$ & $-.8985 * *$ & $-.3956 * * *$ \\
\hline & & $(.022)$ & $(.001)$ & $(.027)$ & $(.003)$ \\
\hline \multirow[t]{2}{*}{ South } & Central & $-2.289 * *$ & $-1.375 * * *$ & $-.0956 * *$ & $-.2112 * *$ \\
\hline & & $(.016)$ & $(.003)$ & $(.048)$ & $(.045)$ \\
\hline \multirow{2}{*}{\multicolumn{2}{|c|}{ Central }} & $-2.534 * *$ & $-1.163 * *$ & $-.4738 * * *$ & $-.2097 * *$ \\
\hline & & $(.046)$ & $(.024)$ & $(.001)$ & $(.042)$ \\
\hline \multirow{2}{*}{\multicolumn{2}{|c|}{ Southeast }} & $-1.454 * * *$ & $-1.248 * * *$ & $-.2135^{* * *}$ & $-.1218 * *$ \\
\hline & & $(.001)$ & $(.004)$ & $(.000)$ & $(.041)$ \\
\hline \multirow[t]{2}{*}{ Mekong } & River & $-1.559 * *$ & $-1.073 * *$ & $-.2247 * * *$ & $-.1648 * *$ \\
\hline & & $(.046)$ & $(.022)$ & $(.001)$ & $(.045)$ \\
\hline \multirow[t]{2}{*}{ INFR } & & $.0719 * * *$ & $.0833 * * *$ & $.0786 * * *$ & $.0901 * * *$ \\
\hline & & $(.002)$ & $(.005)$ & $(.000)$ & $(.001)$ \\
\hline \multirow[t]{2}{*}{ EDU } & & $.1246^{* * *}$ & $.1232 * *$ & $.1185^{* * *}$ & $.1248 * * *$ \\
\hline & & $(.000)$ & $(.019)$ & $(.000)$ & $(.007)$ \\
\hline \multirow{2}{*}{\multicolumn{2}{|c|}{ RINT }} & $-.1078 * *$ & $-.1134 * *$ & $-.1056 * *$ & $-.1213 * *$ \\
\hline & & $(.032)$ & $(.025)$ & $(.018)$ & $(.041)$ \\
\hline
\end{tabular}

Observations: 448; average RMSE for the system: 0.3867; average p-value for the model: 0.001; p-values for White test: 0.476; p-value for the AR (1): 0.203; p-value for the AR (2): 0.749 .

Notes: $* * *, * *, *$ indicate significant level at $1 \%, 5 \%$, and $10 \%$ respectively; p-values are in parentheses. 
Finally, we repeat the calculations using the original data for the even years and find similar results concerning the signs, the magnitudes, and the significant levels with slightly more volatile p-values. These results are available upon requests and as expected because the FE3SLS render more stable test results with larger data.

\section{POLICY IMPLICATIONS}

Based on the results, several suggestions on economic policy are forwarded. First, since the level of development is important in reducing the disaster damages through investment, there is a need to extend aids by domestic and international organizations to mitigate poverty and developmental factors such as education, healthcare, and other social supports. Second, damage preventive activities ex-ante have been diligently carried out by Vietnamese people and made great contribution to damage reduction expost. The central and local governments have been very active in evacuation efforts as well. However, updated information on November 18 showed that Typhoon Haiyan, which made its landfall in the North instead of the Central on November 10, and its aftermath still left numerous dead, injured, and thousands of houses damaged. The central and local governments should strengthen their help in forms of forecasting adjustments, technical guidance, and human resources to improve preventive activities.

Finally, since inter-regional and intra-regional trade depends heavily on infrastructure such as roads, bridges, and telecommunication, Vietnamese central and local governments should reinforce the protection of the infrastructure system before and improve it after each disaster to maintain and quickly reconnect the regional grids of transportation and communication for domestic trade activities.

The lack of data on other variables, for example, public and private expenditures on preventive activities or retail-sale values at household levels, might lend less reliable results. In particular, the lack of yearly data on household income may be hindering a precise estimation of the microeconomic effects on the economy. Additionally, it will be interesting to see the effect of disaster damages on each of the 64 sub-regions and the difference between urban and rural areas. These issues are left for future research

\section{References}

Albala-Bertrand. M. J. (1993), "Natural Disaster Situations and Growth: A Macroeconomic Model for Disaster Impacts", World Development. 21, 9, 1417-1434.

Barro, R.J. \& X. Sala-i-Martin (2004), Economic Growth, MIT Press, Cambridge. 
Bond, S. (2002), "Dynamic Panel Data Models: A Guide to Micro Data Methods and Practice", CEMMAP working paper, CWP09/, 02.

Center for Research Epidemiology of Disasters (2013), "Emergency Events Database", http://emdat.be/

Cuaresma, J.C., J. Hlouskova, \& M. Obersteiner (2008), "Natural Disasters as Creative Destruction? Evidence from Developing Countries,” Economic Inquiry, 46(2), 214-226.

Greene, W. (2003), Econometric Analysis, Fifth Edition. Pearson/Wesley, Princeton, NJ.

Halliday T. (2006), "Migration, Risk and Liquidity Constraints in El Salvador", Economic Development and Cultural Change, 54(4), 893-925.

Horwich G. (2000), "Economic Lessons of the Kobe Earthquake", Economic Development and Cultural Change, 521--542.

Kennedy, P. (2008), A Guide to Econometrics, Sixth Edition, MIT Press, MA.

Noy, I. \& Vu, T.B. (2010), "The Economics of Natural Disasters in a Developing Country: The Case of Vietnam", Journal of Asian Economics, 21, 345-354.

Paxson, C. H. (1992), "Using Weather Variability to Estimate the Response of Savings to Transitory Income in Thailand”, American Economic Review, 82(1), 15--33.

Schumpeter, J. (2008), Capitalism, Socialism and Democracy, New York, Harper [original publication in English, 1943].

Selcuk, F. \& E. Yeldan (2001), "On the Macroeconomic Impact of the August 1999 Earthquake in Turkey: A First Assessment”, Applied Economics Letters, 8, 483--488.

Skidmore, M. \& H. Toya (2002), “Do Natural Disasters Promote Long-Run Growth?” Economic Inquiry, 40(4), 664-687.

United Nations Office for Disaster Risk Reduction (2013), Disaster Inventory System/Disaster Information Management System website, http://www.desinventar.net/

Wooldridge, J. (2003), Introductory Econometrics: A Modern Approach, Thompson, Ohio. 


\section{APPENDIX}

Bond (2002) is a refined application of the Arellano \& Bond (1991) and the Arellano \& Bover (1995) procedures. Arellano \& Bond (1991) developed the differenced GMM estimator for dynamic panels. The method accounts for lagged dependent variables that are predetermined but not exogenous: they are independent of current disturbances but may be influenced by past ones. Differencing the lagged dependent variables or taking deviations from the mean will eliminate the fixed effects. Nonetheless, the differenced GMM produces biased coefficient estimates and unreliable tests when an endogenous variable is close to a random walk. In this case, past values provide little information about future changes, so the untransformed lags are weak instruments for transformed variables.

To solve this problem, Blundell \& Bond (1998) develop a modified procedure introduced in Arellano \& Bover (1995). In this approach, they add the difference of the instrumental variable (IVs) to make them exogenous to the fixed effects. In order to build this while retaining the original Arellano-Bonds for the transformed equation, they design a system GMM estimator while left-multiplying the original data by a transformation matrix, $Z_{+}^{*}=\left[\begin{array}{c}Z^{*} \\ I\end{array}\right]$, where $Z^{*}$ is the differenced matrix. Hence for individual $\mathrm{i}$, the new data set is $X_{i+}^{*}=\left[\begin{array}{c}X_{i}^{*} \\ X_{i}\end{array}\right], \quad Y_{i+}^{*}=\left[\begin{array}{c}Y_{i}^{*} \\ Y_{i}\end{array}\right]$.

When an endogenous variable is close to a random walk, past changes are more predictive of current levels than past levels are of current changes, so the new instruments add extra controls to the original ones for models with lagged dependent variables. Hence, the Blundell-Bond (1998) approach effectively controls autocorrelation and heteroskedasticity, provides consistent coefficient estimates, and performs more reliable tests for autocorrelations and Sargent tests for over-identifying restrictions than the original Arellano-Bond (1991). Estimating the reduced forms in System (3) using the Blundell-Bond GMM procedure will sufficiently solve the problems in model with lagged dependent variables. The predicted values of $D M S, Y$, and $I N V$ then are used as IVs in the FE3SLS estimations for System (2). 